\title{
BOtANICAL SCIENCES A 75 AÑOS, LOS OtROS DATOS DE LA HISTORIA
}

Agradezco al Dr. Salvador Arias la gentil invitación de participar en esta celebración del $75^{\circ}$ aniversario del comienzo de la publicación del Boletín de la Sociedad Botánica de México. No he estado presente en ese inicio; tampoco he servido directamente en calidad de editor de la revista, pero fui testigo de la mayor parte de su vida y de su evolución, por lo que he de ofrecer ahora un breve análisis histórico de este principal instrumento encargado de dar a conocer los resultados de labor botánica en nuestro país. Si bien Jorge Meave ya ha abordado el tema en más de una ocasión, procuraré hacer énfasis en enfoques algo diferentes.

Para ubicar el contexto en el que nace la revista, es importante recordar que como consecuencia de los prolongados conflictos de la Revolución, a partir del año 1910 México entró en un lapso de declive económico que repercutió también severamente en el desarrollo de la vida cultural, académica y científica. Así, en la década de 1940 no se contaba más que con cinco botánicos activos, de los cuales dos eran inmigrados. No vivían en la miseria, pero para sostenerse tenían que recurrir a varios empleos, pues los salarios distaban de ser suficientes. Prácticamente no existían fondos ni mecanismos de apoyo para la realización de las labores de investigación y menos para el trabajo de campo.

Aun así, la investigación científica no estaba ausente en México. La impulsaron individuos y mentes particularmente entusiastas y con firme convencimiento de que su esfuerzo favorecería el futuro del país y de su pueblo. Una de estas personas era Maximino Martínez, maestro normalista y botánico autodidacta, ya desde hacía algún tiempo invitado a laborar en el Instituto de Biología de la Universidad Nacional Autónoma de México.

En 1941 se funda la Sociedad Botánica de México, misma que en 1944 abre la publicación de su Boletín, ambos como resultado de la iniciativa de Martínez y gracias a cuya visión, profundo empeño, generosidad y persistencia, ambos pudieron mantenerse con vida durante los primeros quince años de su existencia.

El inicio del Boletín no fue fácil pues, a semejanza de lo que está ocurriendo ahora, éste no lograba captar los resultados de trabajos botánicos más significativos realizados en su época. Ya estaban activos entonces los Anales del Instituto de Biología (desde 1930), la Revista de la Sociedad Mexicana de Historia Natural y los Anales de la Escuela Nacional de Ciencias Biológicas (a partir de 1939) y también Ciencia (establecida en 1940). En tal circunstancia, lo publicado en los primeros tres números no califica todavía como contribución científica substancial. Más adelante, en forma paulatina comienzan a aparecer artículos de interés florístico, taxonómico y etnobotánico de cada vez mayor valor e interés. El número 13 (1951) incluye un trabajo de tinte ecológico y en los números 14 (1952) y 15 (1953) se describen por primera vez especies nuevas de monocotiledóneas, de la pluma de Eizi Matuda. En el número 21 (en 1957) el Boletín inicia el registro de la ayuda económica recibida del Instituto Nacional de la Investigación Científica. El 23 es de 165 páginas y está dedicado como homenaje a Faustino Miranda, con la intervención de10 autores, algunos de ellos extranjeros, varios escribiendo en inglés. En 1960 (número 25) se revela la novedad de la existencia de un comité editorial de la revista y en 1963 (número 28) se publica el clásico y ampliamente reconocido trabajo de Miranda y Hernández Xolocotzi intitulado "Los tipos de vegetación de México y su clasificación".

A partir de 1965 poco a poco se van diversificando los temas de los artículos publicados para incluir los relacionados con la citogenética, fitogeografía, anatomía, palinología, fisiología e historia de la botánica. Por otro lado, sin embargo, los habituales problemas financieros de la Sociedad han ocasionado retrasos en la frecuencia de la publicación del Boletín y así ha faltado su aparición en 1964, 1966, 1967, 1968, 1971, 1973, 1975, 1978 y también en 1985 y 1986. Desde 1974 (número 33) figura en el Boletín la función del jefe del Comité Editorial y al principio de la década de 1980 comienza a aplicarse la revisión obligatoria de los trabajos por parte de dos revisores anónimos. El número 49 (de1989) está íntegramente dedicado a trabajos de ecofisiología vegetal y organizado por Carlos Vázquez Yanes. La época de los años 90as marca el inicio de cambios trascendentes, pues en ese lapso entra en vigor la novedosa evaluación cuantitativa del trabajo científico, proceso que atañe en primera instancia a las revistas correspondientes, inicialmente en el extranjero, pero pronto también en México. Igualmente es el tiempo en que el Consejo Nacional de Ciencia y Tecnología (activo desde 1971) comienza su labor de búsqueda de la elevación del nivel de las publicaciones nacionales y establece el "Índice de Revistas Mexicanas de Excelencia”.

En la práctica tales innovaciones han significado la existencia de presiones cada vez más intensas para el ajuste a numerosas rutinas exigidas. Inicialmente, entre otras cosas, eran la periodicidad y puntualidad de la publicación, la rapidez del proceso editorial de los manuscritos, la incorporación de la versión electrónica. Con el transcurso del tiempo han surgido muchas otras, como la obligación de emplear el Open Journal System (OJS) y la aceptación preferente (o exclusiva) de trabajos escritos en inglés. Como una de las consecuencias, en 1994 se decide el cambio a un solo editor responsable del Boletín, por lo que el comité asume solamente funciones secundarias. En esa ocasión le toca el puesto a Ken Oyama,

This is an open access article distributed under the terms of the Creative Commons Attribution License CCBY-NC (4.0) international. https://creativecommons.org/licences/by-nc/4.0/ 
gracias principalmente a cuyo esfuerzo e influencia, desde entonces la revista se publicó con regularidad dos veces al año. También aparece con formato, estilo y organización modernizados. El número inicial (55) de esta nueva apariencia, está dedicado a artículos de especialistas en diferentes ramas de la botánica para analizar las respectivas visiones de su desarrollo en México. Pronto, además de la versión impresa, la revista se incorpora al internet y los artículos comienzan a estar disponibles allí para su lectura. Siguiendo esta línea de avance tecnológico, hoy puede consultarse libremente, incorporado en su portal electrónico, todo el acervo del Boletín a partir de su inicio en 1944.

El año 2011 y la abrumadora preponderancia del uso del idioma inglés en la comunicación científica, marcan el inicio de una nueva era para la revista. El Boletín de la Sociedad Botánica de México se convierte en Botanical Sciences; su numeración de fascículos individuales queda sustituida por la de volúmenes anuales $\mathrm{y}$, dado el incremento de manuscritos recibidos, cada uno consiste ahora de cuatro entregas de aparición trimestral. Además, en congruencia con los actuales hábitos de lectura y consulta, se discontinua su impresión y su anterior amplia y costosa distribución a bibliotecas y miembros de la corporación. Aunque recibió críticas, el cambio ha funcionado de manera satisfactoria y ofrece un futuro prometedor.

Vistos de ahora, los 75 años transcurridos no solamente son historia; son un formidable testimonio del relevante papel que la revista ha desempeñado y sigue desempeñando al servicio de nuestra comunidad. Para concluir, deseo volver a llamar la atención sobre el hecho de que el inapropiado sistema de evaluación de la labor científica, que está en boga, ha desviado profundamente el desenvolvimiento correcto de la botánica en México. Uno de sus resultados más palpables es la huida a publicaciones extranjeras de una creciente proporción de los buenos trabajos realizados en el país. Esta es una poderosa rémora de la revista.

Jerzy Rzedowski, 2019

Investigador Emérito 